\title{
Segregación y Heterodoxia
}

\author{
Poco ortodoxa | Anna Winger | 2020 \\ Verónica Lull Casado* \\ Universidad de Buenos Aires
}

Recibido 19 de mayo 2020; aprobado 6 de julio 2020

\begin{abstract}
Resumen
El artículo toma como referencia la serie Unorthodox (traducida al español como Poco ortodoxa) y desde allí trabaja la segregación desde dos perspectivas: desde la comunidad y en relación a la protagonista, Esther Shapiro.

En la vía de la comunidad, desliza desde la segregación estructural hasta la localización del rechazo del extranjero como respuesta estereotipada en relación a lo traumático. El texto avanza desde la noción de masa hasta la de comunidad de goce.

En la vía de la protagonista, sigue el movimiento subjetivo que conduce a la joven a sortear el mecanismo segregativo y dar el paso en la dirección de la separación y la construcción de un nuevo semblante y un nuevo cuerpo. El texto recorre aquí el camino del sujeto en la realización del deseo.
\end{abstract}

Palabras Clave: segregación | comunidad | deseo | goce

Segregation and Heterodoxy

\begin{abstract}
The article focuses its analysis on the Unorthodox series and develops an idea of the topic of segregation. These idea is raised from two perspectives: from the community and from the protagonist, Esther Shapiro.

From the community perspective, it raises structural segregation inside the relationship between the members of a group and the foreign people. In the protagonist's perspective, the article follows the subjective process that leads the young woman to overcome the segregative mechanism and move along to separation and the construction of a new subjectivity. The text goes through the path of the subject in the realization of desire.
\end{abstract}

Keywords: segregation | community | desire | enjoyment

Unorthodox, traducida al español como Poco ortodoxa, describe de un modo particularmente conmovedor el drama en el que transcurre cierto momento de la vida de Esther, protagonista de la película. La intensidad dramática radica probablemente en que el proceso de emancipación de la joven se encuentra narrativamente condensado en cuatro episodios.

De entrada se presenta el conflicto que tracciona a la protagonista hacia los senderos de la liberación: y es que Esther está presa del sentido. La religión en la que ha sido criada, las normas culturales de la comunidad a la que pertenece, los códigos de su familia de origen y los de su familia política ... su mundo entero está plagado de sentidos que la someten, la aprisionan, la asfixian.

Esther Shapiro es una joven de diecinueve años casada desde hace un año con un joven también perteneciente a la comunidad jasídica Satmar residente en el barrio de Williamburg en Nueva York. Desde el principio, algo en el film parece indicar que la cosa, para la joven, no marcha como ella anhelara. Sin embargo, cualquier cambio al interior de esa comunidad puede ser concebido como transgresión.

En este marco, Esty concentra desde el inicio una rebeldía sofocada que la convierte prontamente en un personaje pleno de potencial. Hay en ella una mujer luchando por una dignidad que -aunque no conocida- se ansía como necesaria.

El conflicto que viene in crescendo desde las primeras escenas se precipita de pronto con el pedido de divorcio por parte de Yanky, esposo de Esther. El argumento de éste y el modo en que formula su petición -a instancias del criterio materno- arranca a la joven de cualquier escena conyugal posible con ese hombre. Y toma la decisión de huir.

* llullcasadoveronica@gmail.com 


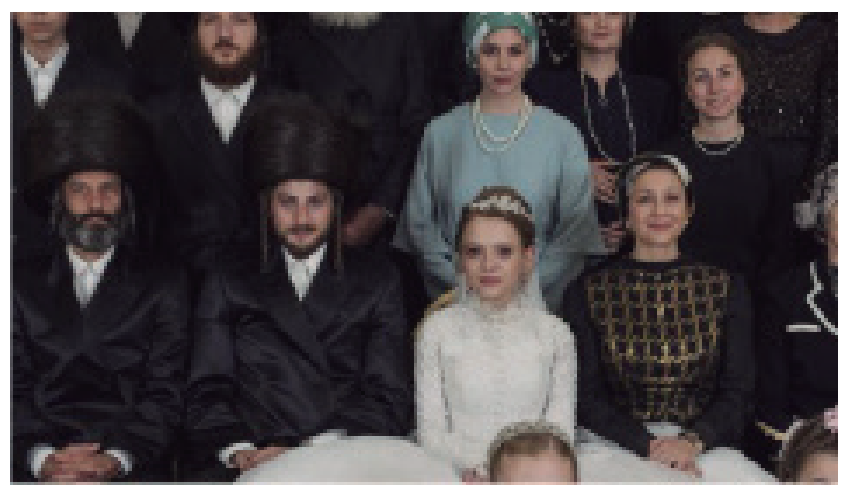

\section{Trauma y repetición. Comunidad de goce}

La comunidad jasídica Satmar está conformada en su mayoría por descendientes de sobrevivientes húngaros del régimen nazi. La segunda y tercera generación de la comunidad se forjó sobre el suelo dicho o silenciado del horror. Los campos de concentración constituyen la marca traumática en torno de la cual se nuclean los sobrevivientes y su descendencia.

Este dato no es un dato menor. G. Agamben (1998) señala el efecto que tiene sobre el sobreviviente no sólo la huella de la experiencia del campo de exterminio sino además el hecho de haber sobrevivido a él -los afectos diversos que se enlazan con esto.

La película -muy freudianamente- plantea esta hipótesis en boca del patriarca: la liturgia de rememoración de las distintas esclavitudes del pueblo judío, desde los egipcios hasta el nazismo. Y se adentra de tal forma en el corazón mismo de la segregación.

Dice el patriarca en referencia a los pueblos extranjeros, "cada vez que hablamos su lengua, Dios nos castigó”. El extranjero implica un peligro. El mundo, ahí afuera, más allá de los límites precisos de la comunidad, puede ser un universo muy hostil. La comunidad se vuelve así en una suerte de reaseguro contra lo inquietante de una lengua nueva. El castigo como argumento del peligro de la exogamia revela el núcleo basal de la segregación.

Lo interesante en la enunciación del patriarca es que transmite a su clan el fundamento mismo del lazo como alianza. Hablan en su voz S. Freud y J. Derrida.

La segregación constituye el mecanismo fundacional de la estructura (Freud, 1930). Se trata de una idea con la que el autor recupera un tempranísimo planteo en relación a la constitución del complejo del semejante (Freud, 1894). El sujeto rechaza de sí lo que genera perturbación.
Y eso, inquietante, pasa a constituir el campo de lo ajeno, lo exterior, y aún más, lo hostil.

La hostipitalidad (Derrida, 2006) es el neologismo con el que el autor nombra lo hostil al interior del gesto hospitalario. El huésped puede entrañar el peor de los peligros para quien ofrece su casa como alojamiento. Y al mismo tiempo, el ofrecimiento de un lugar al extranjero puede llevar implícito un gesto hostil. Así el lazo social supone en su núcleo mismo un elemento resistente a la unidad, ajeno a la unificación, refractario a la síntesis. En el fundamento mismo de la masa (Freud, 1921) se esconde lo ominoso (Freud, 1919).

La comunidad jasídica testimonia con su abroquelamiento, el carácter profundamente perturbador del lazo social, aún en términos de alianza. No alcanza con aferrarse a las normas religiosas al interior de la comunidad -no alcanza con la transmisión que de ellas se haga a los propios a fin de garantizar la perpetuación del código y con él del Nombre del Padre. Hace falta además que todos los sentidos de la religiosidad preserven al sujeto del peligro que comporta lo heterodoxo -es decir, todo aquello que se aparte de la pauta cultural establecida.

En este establishment, lo heterodoxo va desde lo extranjero, lo extra comunitario hasta lo femenino al interior del propio pueblo.

Es elocuente en el film el tratamiento discursivo que se le da a la madre de Esther. Esta mujer, casada a sus diecisiete años con un hombre alcohólico al que no amaba y que jamás deseó y que -huelga decir-no había elegido, concentra todas las miradas hostiles en el punto en que encarna el misterio de un arrojo por fuera de los límites de la comunidad.

Extranjera (proveniente de Inglaterra), refractaria a la lengua materna (reacia al uso del idish), heterodoxa en su preferencia sexual (lesbiana) y finalmente, desertora de la comunidad (esposa fugada y exiliada en Alemania), la madre de Esty reúne todas las condiciones para ser el blanco de la segregación necesaria a la estructura de la comunidad.

Y es que Freud (1921) lo sitúa muy claramente. La estructura de la masa -por la identificación de sus miembros entre sí a través de su lazo al Ideal- tiende a anular las diferencias. O más bien, las opaca, las suaviza, en una tendencia a la homogeneización que, sin embargo, resiste preservando como identidad, las púas de los puercoespines.

Resulta verdaderamente interesante el modo en que el autor se esfuerza por localizar la pieza que en lo imaginario del lazo y aún, en la fortaleza del sostén simbólico de la masa, resiste a cualquier síntesis. Cuando el lazo se 
estrecha mucho, las púas se hacen notar. Conviene por tanto, mantener algo de distancia. La separación al interior del vínculo preserva de la hostilidad inexorable al interior de eso a lo que llamamos lo social. Lo ominoso habita al interior de lo familiar. Lo unheimilich (Freud, 1919) acecha agazapado.

J. Lacan (1969) localiza la segregación en el fundamento mismo de la fraternidad. Es decir que la fraternidad ya es allí un sentido con el que se recubre el mecanismo estructural segregativo. El patriarca lo enuncia de un modo eficaz. La fraternidad como alianza comunitaria constituye el tratamiento defensivo frente a la segregación fundacional.

La segregación forma parte de la mitología estructurante de la religión del pueblo judío. Localizada en los tiempos inaugurales de la esclavitud egipcia y deslizándose hasta nuestros días, obliga al pueblo elegido a unirse para sobrevivir. Hay en esa unidad un fondo reactivo a la hostilidad padecida, al rechazo soportado, al racismo vivenciado a lo largo de la historia.

El sentimiento de pertenencia tan fuertemente arraigado en la comunidad jasídica no esconde su fundamento: radica en la firme convicción del padecimiento de la segregación a lo largo de la historia de la comunidad judía. Desde esta perspectiva, la segregación secundaria en su interior constituye entonces un acto de defensa y un sentido de afirmación cultural.

No hace falta ninguna ideología para el ejercicio del racismo; hace falta sólo la localización de un plus de gozar (Lacan, 1970). Y el pueblo judío sabe de qué puede ser capaz el deseo que se realiza bajo el modo de una oscura voluntad de goce: el goce del exterminio de la diferencia (Delgado, 2005).

He ahí la forma que toma el racismo bajo el régimen nazi. Por eso Lacan postula que el mismo avanza más allá de cualquier argumento ideológico. Alcanza con localizar un goce hétero y avanzar en la pretensión de eliminarlo. Luego la ideología sirve como un argumento de legitimación, incluso de dominación política.

La comunidad jasídica se presenta como una respuesta reactiva al trauma del genocidio. El abroquelamiento en torno del fuerte sentido de pertenencia y la transmisión cultural en torno del Nombre del Padre como elemento ordenador de la estructura, garantiza al pueblo una fortaleza frente al avance del enemigo, una construcción de piedra en la que guarecerse del peligro que representa el mal.

Freud (1939) describe los efectos del trauma en la subjetividad. Repetición del trauma y evitación del mismo. Ambos dan cuenta de la fijación de goce que el mismo entraña. En el discurso jasídico parece adivinarse la lógica freudiana. La masa que, en la comunidad de Williamburg, nuclea a sus miembros en torno del padre asegurándoles la protección del peligro a través de la providencia de Dios.

Si Dios es el sentido que el hablante le da al desamparo (Freud, 1932) no parece descabellado que la religión y el lazo que ésta garantiza le otorguen a la comunidad jasídica un texto con el que tramitar el horror del exterminio nazi. Sin embargo, al interior de la comunidad, también habita el goce. O, para decirlo mejor, toda comunidad implica una alianza de goce. El problema se presenta cuando, un miembro de esa comunidad, da cuerpo a un goce Otro. La segregación vuelve a ser entonces el mecanismo por el cual la estructura de la masa opera defendiéndose. Esther Shapiro sabe de esto.

\section{Del rechazo de lo femenino a una versión de mujer}

Esty se presenta de entrada como una chica diferente. Se lo dice a Yanky al conocerlo y con esa proclamación parece estar anticipando un pedido. Hay en su enunciación una demanda. Ella sabe que hay algo de sí que se adivina refractario a esa comunidad y pretende lógicamente, ser reconocida en su singularidad y que de ese modo, se la aloje. Yanky no tardará en hacerle saber que eso no es posible.

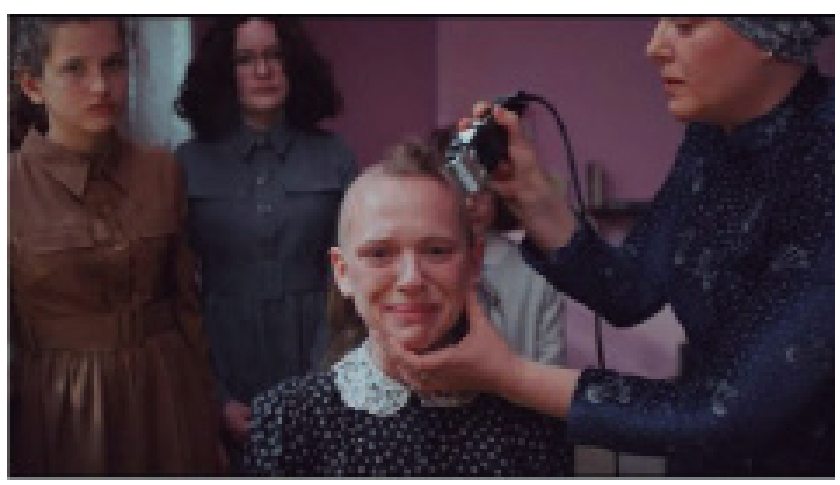

El film muestra algunos de los códigos de la religiosidad jasídica que más restricciones comportan para las mujeres. Desde el velo -elemento que la religión comparte con otras religiones tales como la musulmana e incluso la católica- hasta el tabú del período menstrual y la prohibición de cantar en público.

Hay en la comunidad una pauta religiosa que hace del pudor -del lado de ella- el velo con el que se recubre el 
cuerpo de una mujer. Su reverso, cada uno de los tabúes de contacto del varón en torno de la femineidad. Prontamente se revela el carácter enigmático de lo femenino y la atribución de hostilidad con que el varón puede abordarlo (Freud, 1918; Delgado, 2005).

La lógica fálica no inscribe la diferencia sexual. "Hay algo masculino, pero no algo femenino" (Freud, 1923, p 149). El falo inscribe la diferencia en términos de castración. Tiene o le falta, esa es la polaridad. La sexualidad femenina queda por esta vía marcada por el menos. Los semblantes que hacen juego con ese menos $(-\nabla)$ son los que permiten dar una respuesta a la pregunta por la femineidad -del lado varón de la fórmula, se trate de la histeria o del macho. (Lacan, 1972).

El abordaje de lo femenino del lado hombre de la fórmula entraña entonces al menos dos posibilidades: por la vía de la atribución de una significación ligada con el menos -y entonces aparecen los semblantes de la mujer pobre, tonta, vieja, fea- o por la vía de la atribución de alguna relación de esa mujer al falo como bien -se desencadena entonces la hostilidad en el tratamiento de lo hétero- la bruja, la patrona...

En el film, Esther ocupa un lugar idealizado en relación al partenaire que eligieron para ella. Yanky, lejos de verla como una mujer habitada por el deseo, sólo puede concebirla como madre de los hijos que anhela tener. Incapaz de localizar en ella algo más que una expectativa fálica-materna, se dedica a desconocer durante un año las vías del erotismo que les hubiera permitido algún encuentro sexual posible. Yanky rechaza así lo femenino en Esty degradándolo a lo materno. Aborda ese enigma por la vía de la significación fálica en términos de castración.

Ahora bien, lo femenino no logra reducirse a esta lógica. Una mujer se enlaza no toda al falo. La dimensión del objeto permite a Lacan (1972) dar cuenta de eso que resta como enigma. Se trata de una vía del deseo que abre al campo del goce. Otro goce -esta vez, por fuera del goce fálico.

Es desde esta perspectiva que la sexualidad femenina resulta enigmática aún para quien se encuentra desde la anotomía, en apariencia, menos obstaculizada por el falo. Es así que la segregación de lo femenino por extranjero respecto de la lógica fálica no es solo privativa del varón. El rechazo con el encuentro de eso Otro que habita en ella puede resultar inquietante y hasta ominoso al interior de la propia subjetividad femenina. La histeria y sus inhibiciones dan cuenta de ello.

Hay algo en Esther que le resulta enigmático a ella de sí misma. Hay algo en esa identidad de mujer jasídica que no termina de asimilar lo heterogéneo del elemento que la habita. Hay en ella un deseo que resiste cualquier reducción fálica. Y hay incluso un goce que no se deja domesticar bajo esa norma. La advertencia había sido hecha desde el inicio. Esty se había afirmado en su singularidad como diferencia.

En esa encrucijada se encuentra cuando su marido le pide el divorcio. Desalojada de la escena en la que se había sostenido muy a su pesar durante todo ese año, Esther decide irse. La huida se presenta como un acto de separación. Esther se libera del sentido que la oprime y pone a jugar el objeto separador (Lacan, 1964). Aparecerá entonces su voz.

El cuerpo adquiere en este segundo tramo toda su presencia. Esty comienza a transitar un proceso de construcción de un nuevo semblante con el que recubrir lo real de su femineidad (Miller, 1993). Ya no se trata del sentido represivo de ser-una-mujer-jasídica-nacida-para-ser-madre-que-sólo-tiene-sexo-con-la-finalidad-deprocrear.

El film no lo muestra - ¿acaso un signo de pudor?pero en el encuentro con el joven alemán se adivina la dimensión del erotismo. Esty descubre otro cuerpo. Su propio cuerpo más allá del sentido de la religiosidad como argumento represivo de la sexualidad. Hay sexualidad ligada al placer -más allá de la finalidad reproductiva. Un hombre puede gustarle.

Comienza a desplegarse así la pregunta por la femineidad recorriendo otros senderos que el de los sentidos fuertemente coagulados hasta entonces. Esther transita un proceso de feminización ligado a los cánones occidentales que incluyen desde el cambio de su vestimenta hasta la mascarada (Lacan, 1957) del maquillaje. Se trata del encuentro con nuevas formas del velo ligadas a los semblantes que Occidente le ha dado a la femineidad. Detrás de ese nuevo ropaje simbólico imaginario comienza a recortarse el objeto que le permitirá la separación. La voz abre así hacia otra vía.

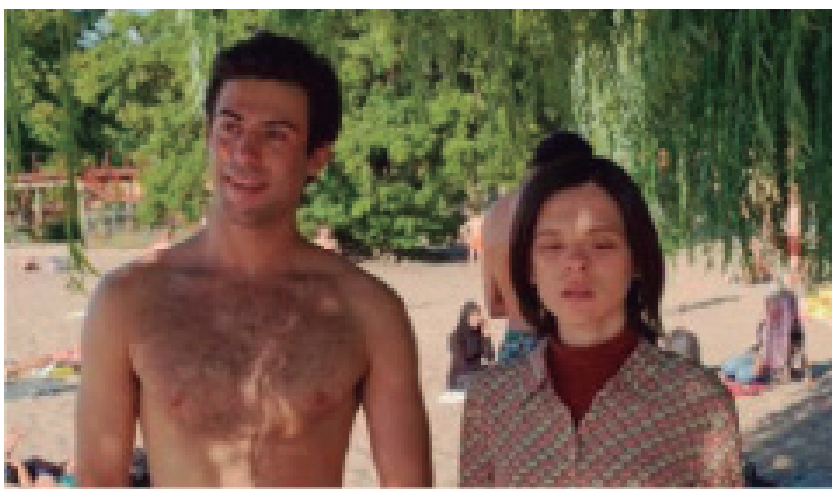


Carente de educación formal, habiendo crecido en una comunidad que la educó para ser esposa y madre sin tener que llegar a valerse por sí misma jamás -entendiendo que siempre habría un hombre proveedor que garantizaría su prosperidad-. Esther decide audicionar en el conservatorio de música.

El viaje iniciático de Esty culmina con la prueba de canto. Esther, mujer y próximamente madre, termina de romper con otro de los sentidos de la religiosidad con la que fue formada. Hace aparecer su voz en público. Su canto seduce al auditorio. El grito del final libera al sujeto del Otro que la alienaba hasta entonces (Lacan, 1963).
Hay aquí una nueva versión de la femineidad para ella. Una mujer como voz de liberación. Una mujer como grito separador del Otro. La dimensión del objeto como respuesta a la pregunta por el enigma del deseo y el goce femeninos. Ya no se trata sólo de la dimensión del semblante. Ahora es el cuerpo en su dimensión real el que está en juego.

Esther ha dado el paso que faltaba: poner a jugar su propia voz de mujer en ese mundo de hombres con el que hasta entonces dialogaba. Ahora ella habla con un mundo más allá de las fronteras geográficas de su comunidad. Ha hecho oír su voz y ha encontrado en esto un goce. He ahí su acto más radical.

\section{Referencias}

Agamben, G. (1998). Lo que queda de Auschwitz. Adriana Hidalgo Editora.

Delgado, O. (2005). La subversión freudiana y sus consecuencias. JVE Ediciones.

Derrida, J. (2006). La hospitalidad. Ediciones de la flor.

Freud, S. (1895). Proyecto de Psicología para neurólogos. Obras Completas. Vol I. Amorrortu Editores.

Freud, S. (1918). El tabú de la virginidad. Obras Completas. Vol XII. Amorrortu Editores.

Freud, S. (1919). Lo ominoso. Obras Completas. Vol XVII. Amorrortu Editores.

Freud, S. (1921). Psicología de las masas y análisis del yo. Obras Completas. Vol XVIII. Amorrortu Editores.

Freud, S. (1923). La organización genital infantil. Obras Completas. Vol XIX. Amorrortu Editores.

Freud, S. (1930). El malestar en la cultura. Obras Completas. Vol XXI. Amorrortu Editores.

Freud, S. (1932). El porvenir de una ilusión. Obras Completas. Vol XXI. Amorrortu Editores.

Freud, S. (1939). Moisés y la religión monoteista. Obras Completas. Vol XXIII. Amorrortu Editores.

Schrader, M. (2020). Unorthodox [Serie de televisión]. Studio Airlift; Real Film Berlin Gmbh

Lacan, J. (1957). El Seminario: Libro 5. Paidós.

Lacan, J. (1963). El Seminario: Libro 10. Paidós.

Lacan, J. (1964). El Seminario: Libro 11. Paidós.

Lacan, J. (1969). El Seminario: Libro 17. Paidós.

Lacan, J. (1970). El Seminario: Libro 18. Paidós.

Lacan, J. (1972). El Seminario: Libro 20. Paidós.

Miller, J.A. (1993). De mujeres y semblantes. Cuadernos del Pasador. 